\title{
Cobalt removal from wastewater using pine sawdust
}

\author{
Evans T. Musapatika ${ }^{1}$, Ruella Singh ${ }^{1}$, Krishnie Moodley ${ }^{1}$, Charles Nzila $^{2}$, Maurice S. Onyango ${ }^{3}$ \\ and Aoyi Ochieng ${ }^{4 *}$ \\ ${ }^{1}$ School of Chemical and Metallurgical Engineering, University of the Witwatersrand, Private Bag X3 Wits 2050, \\ Johannesburg, South Africa. \\ ${ }^{2}$ Department of Sustainable Organic Chemistry and Technology, Gent University, Coupure Links 653, 9000 Gent- \\ Belgium. \\ ${ }^{3}$ Tshwane University of Technology, Pretoria, Private Bag X680 Pretoria, 0001, South Africa. \\ ${ }^{4}$ Department of Chemical Engineering, Vaal University of Technology, Private Bag X021, Vanderbijlpark, 1900, South \\ Africa.
}

Accepted 27 September 2011

\begin{abstract}
Agricultural wastes can cause environmental problems if not well managed, but there is a lot of potential to use these wastes as raw material in other processes. In this investigation, pine sawdust was evaluated as an adsorbent in the treatment of wastewater containing cobalt ions. A two-level threefactor full-factorial experimental design with centre points was used to study the interactive effect of the operating parameters in order to achieve the best conditions for the batch adsorption of cobalt ions. A response surface analysis was also conducted to further understand the interactions amongst the factors such as adsorbent dose, solution $\mathrm{pH}$ and initial concentration. In addition, adsorption isotherms, namely the Freundlich and Langmuir, were used to characterize the removal of cobalt from the wastewater. It was observed that the combined effect of low adsorbent dose, high $\mathrm{pH}$ and high initial concentration of wastewater resulted in the highest adsorption capacity. The Freundlich isotherm provided a better fit to the experimental data than the Langmuir isotherm. Moreover, pine sawdust showed adsorption capabilities for cobalt, and hence it could be an option in the quest to use waste to treat wastewater.
\end{abstract}

Key words: Adsorption, cobalt, isotherm, sawdust, wastewater.

\section{INTRODUCTION}

Agricultural activities such as the use of fertilizer, pesticide and herbicide contribute to environmental pollution. However, agricultural waste beneficiation is a concept that is rapidly gaining interest. Such beneficiation activities include energy production and wastewater treatment. Increased pollution of water bodies has resulted in strict government regulations on the discharge of toxic waste. In some instances, secondary wastewater treatment is inadequate and tertiary/advanced wastewater treatment methods are required. Advanced wastewater treatment methods include ion exchange (Cavaco et al., 2007), membrane separation (Mavrov et al., 2006),

*Corresponding author. E-mail: ochienga@vut.ac.za. Tel: +2716-950-9884. Fax: +27-16-950-9701. electrolysis (Kurt et al., 2007) and adsorption (Onyango et al., 2004). Most of these methods are costly, require a high level of expertise and therefore limited in application by several end-users. For these reasons, adsorption technology has gained a wider application due to its inherent low cost, versatility and robustness. Thus, the use of agricultural waste-derived adsorbents for wastewater treatment constitutes the main focus of this study.

Recalcitrant organic compounds and non biodegradable inorganic compounds are removed using advanced methods together with secondary methods (Singh et al., 2007). Since industries are forced to comply with stringent effluent discharge regulations, there has been increased research regarding advanced methods of wastewater treatment to remove toxins in wastewater streams. Unfortunately, large capital and running costs are associated with advanced methods. As a measure to 
Table 1. Experimental variable levels and factors.

\begin{tabular}{lcccc}
\hline \multirow{2}{*}{ Factor } & \multirow{2}{*}{ Coded symbol } & \multicolumn{3}{c}{ Levels } \\
\cline { 3 - 5 } & & $\mathbf{- 1}$ & $\mathbf{0}$ & $\mathbf{1}$ \\
\hline Adsorbent dose $(\mathrm{g} / \mathrm{L})$ & $x_{1}$ & 20.0 & 40.0 & 60.0 \\
$\mathrm{pH}$ & $x_{2}$ & 1.3 & 2.6 & 3.9 \\
{$[\mathrm{Co}(\mathrm{II}) \text { and } \mathrm{Ni}(\mathrm{II})]_{\circ}(\mathrm{mg} / \mathrm{L})$} & $x_{3}$ & 0.875 & 1.75 & 2.625 \\
{$[\mathrm{Fe}(\mathrm{III})]_{\mathrm{o}}(\mathrm{mg} / \mathrm{L})$} & $x_{3}$ & 2.125 & 4.25 & 6.375 \\
\hline
\end{tabular}

reduce costs, the concept of using an advanced method of wastewater treatment, such as adsorption with agricultural adsorbents has been applied. In doing so, solid wastes such as coffee husk (Kumar, 2006), peanut shells (Wafwoyo et al., 1999), bagasse (Azhar et al., 2005), rice husk (Kumar and Bandyopadhyay, 2006) and sawdust (Argun et al., 2007), among others, can be used to treat wastewater. These materials can be employed to treat wastewater streams such as acid mine drainage, and those from petrochemical industries and semiconductor fabrication plants.

It is important to remove cobalt from wastewater due to its known toxicity. The effects of acute cobalt poisoning in humans are very serious; among them are asthma-like allergy, damage to the heart, causing heart failure, damage to the thyroid and liver. Cobalt may also cause mutations (genetic changes) in living cells (Rangaraj and Moon, 2002). Furthermore, metallic cobalt or cobalt sulphate are the most plausible causes of cobalt asthma. Also, cobalt has a role in the development of diffuse interstitial lung disease (Linna et al., 2003). With a better awareness of the problems associated with cobalt, research studies related to the method of removing cobalt from wastewater have increasingly drawn attention. The objectives of this study are to determine the adsorption capacity of pine sawdust in terms of mass of cobalt ions adsorbed per unit mass of adsorbent and to investigate the interactive effects of adsorbent dose, $\mathrm{pH}$ and initial concentration on adsorption capacity.

\section{MATERIALS AND METHODS}

\section{Adsorbent preparation and characterization}

Pine sawdust collected from a local company was ground and sieved to a particle size range of 500 to $850 \mu \mathrm{M}$. It was then placed in stainless steel trays and dried in an oven (EcoTherm) at $50^{\circ} \mathrm{C}$ for $24 \mathrm{~h}$. A mass of $100 \mathrm{~g}$ was placed in a $1 \mathrm{~L}$ glass beaker and $660 \mathrm{ml}$ of $0.6 \mathrm{M}$ citric acid solution was added to provide additional carboxyl groups to those on pine sawdust surfaces in order to substantially increase its metal uptake. The mixture was stirred using the Rushton turbine impellers for $30 \mathrm{~min}$, and then separated by vacuum filtration. The wet sawdust was then spread in stainless steel trays and dried in an oven at $50^{\circ} \mathrm{C}$ for $24 \mathrm{~h}$ to remove the moisture, after which the temperature was raised to $120^{\circ} \mathrm{C}$ and maintained for $90 \mathrm{~min}$. The sawdust was allowed to cool and washed five times using hot distilled water $\left(60\right.$ to $\left.80^{\circ} \mathrm{C}\right)$ and then dried at $50^{\circ} \mathrm{C}$ for $24 \mathrm{~h}$ (Wafwoyo et al., 1999). Finally, the temperature was raised to $250^{\circ} \mathrm{C}$ and maintained for $24 \mathrm{~h}$, after which the sawdust particles were removed from the stainless steel trays and stored for adsorption tests. No leaching experiments were carried out to check for the presence of toxic soluble leachate that could possibly emanate from pine sawdust, especially in cases where it had been previously treated with pesticides.

The x-ray diffraction (XRD) spectra of the pine sawdust was obtained using an x-ray diffractometer (PANalytical, Philips PW 1710, EA Almelo, the Netherlands) with $\mathrm{Cu}$ Ka radiation at $40 \mathrm{kV}$ and $50 \mathrm{~mA}$ to determine the present phases (amorphous or crystalline). The spectra were recorded from 10 to $65^{\circ}$ at a scan rate of $1.2^{\circ} \mathrm{min}^{-1}$. In addition, Fourier Transform Infrared (FT-IR) spectra of the pine sawdust before and after adsorption were recorded in the range 500 to $4000 \mathrm{~cm}^{-1}$ on an FT-IR (Bruker, Tensor 27 TPR, Ettlingen, Germany) system to explore the number and positions of the functional groups responsible for adsorption. Also, the surface morphology of the adsorbents was visualized via a scanning electron microscope (SEM, Joel JSM-840, Tokyo, Japan) operated at the accelerating voltage of $20 \mathrm{keV}$.

\section{Synthesis of wastewater}

The stock solutions (1000 mg/L) of $\mathrm{Co}(\mathrm{II}), \mathrm{Ni}(\mathrm{II})$ and $\mathrm{Fe}(\mathrm{III})$ prepared from the metal nitrates were diluted with distilled water to obtain the desired initial concentrations according to the levels specified in Table 1. The zero level concentration of heavy metals (centre point) was ten times that reported by Patel and Mudamwar (2002) for a particular petrochemical wastewater sample. Thus, the medium values in the reported ranges were multiplied by ten and taken as the zero levels in the present study. This was to raise the concentrations to the levels that were less susceptible errors compared to the low values reported. Further, the composition and concentrations of the synthetic aqueous solutions prepared fall within the range of the typical petrochemical wastewater described in the Pollution Prevention and Abatement Handbook (World bank group, 2008), which specifies that heavy metal concentration range is 0.1 to $100 \mathrm{mg} / \mathrm{L}$. The $\mathrm{pH}$ of the solutions was adjusted using either dilute $\mathrm{HNO}_{3}$ or $\mathrm{NaOH}$. A high pH level $(+1)$ of 3.9, which is below the $\mathrm{pH}$ point of precipitation $\left(\mathrm{pH}_{\mathrm{ppt}}\right)$ for each of the metal hydroxides, was chosen to prevent possible precipitation (Al-Degs et al., 2006). All the $\mathrm{pH}$ measurements were done using a $\mathrm{pH}$ meter (LabX Direct-SevenMulti, Mettler Toledo, Columbus, OH, USA) and all the chemicals used were of analytical grade supplied by Merck Chemical Company (Johannesburg, South Africa).

\section{Statistical design of experiments}

The adsorbent dose, $\mathrm{pH}$ and initial concentration were chosen as independent variables and the adsorption capacity, $q_{e}$ as the dependent output response variable. $\mathrm{A} 2^{3}$ full-factorial design with four centre point runs leading to 12 experimental runs were performed (Table 2). The centre point replicates were chosen to verify any change in the estimation procedure and as a measure of the precision property (Ravikumar et al., 2007). For statistical 
Table 2. The two-level three factor full-factorial design with four centre points.

\begin{tabular}{|c|c|c|c|c|c|c|c|c|}
\hline \multirow{2}{*}{$\begin{array}{l}\text { Standard } \\
\text { Order }\end{array}$} & \multicolumn{3}{|c|}{ Coded levels } & \multicolumn{3}{|c|}{ Actual levels } & \multicolumn{2}{|c|}{$q_{\mathrm{e}} \times 10^{-3}(\mathrm{mg} / \mathrm{g})$} \\
\hline & $x_{1}$ & $x_{2}$ & $x_{3}$ & Dose (g/L) & $\mathrm{pH}$ & $\mathrm{C}_{\mathrm{o}}(\mathrm{mg} / \mathrm{L})$ & Observed & Predicted \\
\hline 1 & -1 & -1 & -1 & 20.0 & 1.3 & 0.875 & 11.50 & 8.01 \\
\hline 2 & +1 & -1 & -1 & 60.0 & 1.3 & 0.875 & 1.96 & 5.45 \\
\hline 3 & -1 & +1 & -1 & 20.0 & 3.9 & 0.875 & 24.50 & 28.00 \\
\hline 4 & +1 & +1 & -1 & 60.0 & 3.9 & 0.875 & 5.38 & 1.89 \\
\hline 5 & -1 & -1 & +1 & 20.0 & 1.3 & 2.625 & 13.50 & 17.00 \\
\hline 6 & +1 & -1 & +1 & 60.0 & 1.3 & 2.625 & 15.40 & 12.00 \\
\hline 7 & -1 & +1 & +1 & 20.0 & 3.9 & 2.625 & 56.00 & 53.00 \\
\hline 8 & +1 & +1 & +1 & 60.0 & 3.9 & 2.625 & 20.40 & 24.00 \\
\hline 9 & 0 & 0 & 0 & 40.0 & 2.6 & 1.750 & 7.92 & 7.96 \\
\hline 10 & 0 & 0 & 0 & 40.0 & 2.6 & 1.750 & 8.08 & 7.96 \\
\hline 11 & 0 & 0 & 0 & 40.0 & 2.6 & 1.750 & 7.95 & 7.96 \\
\hline 12 & 0 & 0 & 0 & 40.0 & 2.6 & 1.750 & 8.00 & 7.96 \\
\hline
\end{tabular}

calculations, the variables $X_{i}$ were coded as $x_{i}$ according to the following relationship:

$x_{i}=\frac{X_{i}-X_{0}}{\Delta X}$

Where $x_{\mathrm{i}}$ is the independent variable coded value; $X_{\mathrm{i}}$ is the independent variable real value; $X_{0}$, independent variable real value on the centre point; and $\Delta X$, step change value (Elibol, 2002) of which the values for adsorbent dose, $\mathrm{pH}$ and initial concentration in this case are 2.0, 1.3 and 0.88 , respectively. Table 1 gives the range and the levels of the variables (low and high) investigated in this study.

The quadratic model for predicting the adsorption capacity for cobalt was expressed according to Equation 2:

$Y=\beta_{o}+\beta_{1} x_{1}+\beta_{2} x_{2}+\beta_{3} x_{3}+\beta_{11} x_{1}^{2}+\beta_{22} x_{2}^{2}+\beta_{33} x_{3}^{2}+\beta_{12} x_{1} x_{2}+\beta_{13} x_{1} x_{3}+\beta_{23} x_{2} x_{3}$

where $Y$ is the response predicted by the model, whilst $x_{1}, x_{2}, x_{3}$ are the coded forms of dose, $\mathrm{pH}$ and initial concentration, respectively. The term $\beta_{0}$ is the offset term, $\beta_{1}, \beta_{2}$ and $\beta_{3}$ are linear terms, $\beta_{11}, \beta_{22}$ and $\beta_{33}$ are the quadratic terms, whilst $\beta_{12}, \beta_{13}$ and $\beta_{23}$ are the interaction terms (Bhatia et al., 2009). The analysis of variance (ANOVA) for quadratic model was carried out to establish its statistical significance at $5 \%$ level of significance (95\% confidence level). Design Expert Version 6.0.6 (Stat Ease, Inc., Minneapolis, USA) and Matlab Version 7.0.1 (MathWorks, Natick, Massachusetts) were used for regression and graphical analysis of the data obtained. The statistical significance of the regression coefficients was determined by the Student's $t$-test and $p$-values.

\section{Batch adsorption procedure}

A $100 \mathrm{ml}$ wastewater solution was contacted with the desired mass of sawdust in $250 \mathrm{ml}$ Erlenmeyer flasks. Blank solutions (solution without the adsorbent) were also included and the flasks were covered with parafilm. The mixture was shaken at $250 \mathrm{rpm}$ in an incubator with shaking platform (FSIM-SPO16, Labcon, Johannesburg, South Africa) at $25^{\circ} \mathrm{C}$ for a predetermined contact time of $45 \mathrm{~h}$. The supernatant was separated by filtration. Initial and final heavy metal ion concentrations were determined using the
Atomic Absorption Spectrometer (SpectroAA 55 B, Varian, Victoria, Australia). The response (adsorption capacity, $q_{e}$ ) was calculated as:

$q_{e}=\frac{\left(C_{o}-C_{e}\right) V}{m}$

where $C_{0}$ and $C_{\mathrm{e}}$ are the initial and equilibrium adsorbate concentrations in solution ( $\mathrm{mg} / \mathrm{L}$ ), respectively, $V$ is a known volume of synthetic wastewater (L), and $m$ is a known mass of adsorbent (g).

\section{Adsorption isotherms}

In order to optimize the design of an adsorption system for the removal of adsorbate, it is important to obtain the equilibrium adsorption data. Thus, the equilibrium adsorption isotherm data for cobalt was generated by contacting a fixed amount of sawdust $(4 \mathrm{~g})$ with $100 \mathrm{ml}$ of synthetic wastewater with the concentration of metal ions ranging from 2 to $20 \mathrm{mg} / \mathrm{L}$ in $250 \mathrm{ml}$ flasks. The flasks were shaken at $250 \mathrm{rpm}$ in an incubator with shaking platform at $25^{\circ} \mathrm{C}$ for $45 \mathrm{~h}$. At the end, the residual concentrations of the cobalt ions were measured and the adsorption capacity, $q_{\mathrm{e}}$ was determined. The results were fitted to the commonly used Langmuir and Freundlich isotherms. Equation 4 is the linear form of the Langmuir isotherm:

$$
\frac{1}{q_{e}}=\left(\frac{1}{K_{L} q_{\max }}\right) \frac{1}{C_{e}}+\frac{1}{q_{\max }}
$$

where $q_{\mathrm{e}}$ is the adsorption capacity at equilibrium $(\mathrm{mg} / \mathrm{g}), q_{\max }$ is the theoretical maximum adsorption capacity of the adsorbent $(\mathrm{mg} / \mathrm{g})$, $K_{\mathrm{L}}$ is the Langmuir affinity constant $(1 / \mathrm{mg})$ and $C_{\mathrm{e}}$ is the supernatant equilibrium concentration of the system ( $\mathrm{mg} / \mathrm{L}$ ) (Febrianto et al., 2009). The Freundlich isotherm model can also be expressed in the linearized logarithmic form (Equation 5):

$\log q_{e}=\log K_{F}+\left(\frac{1}{n}\right) \log C_{e}$ 


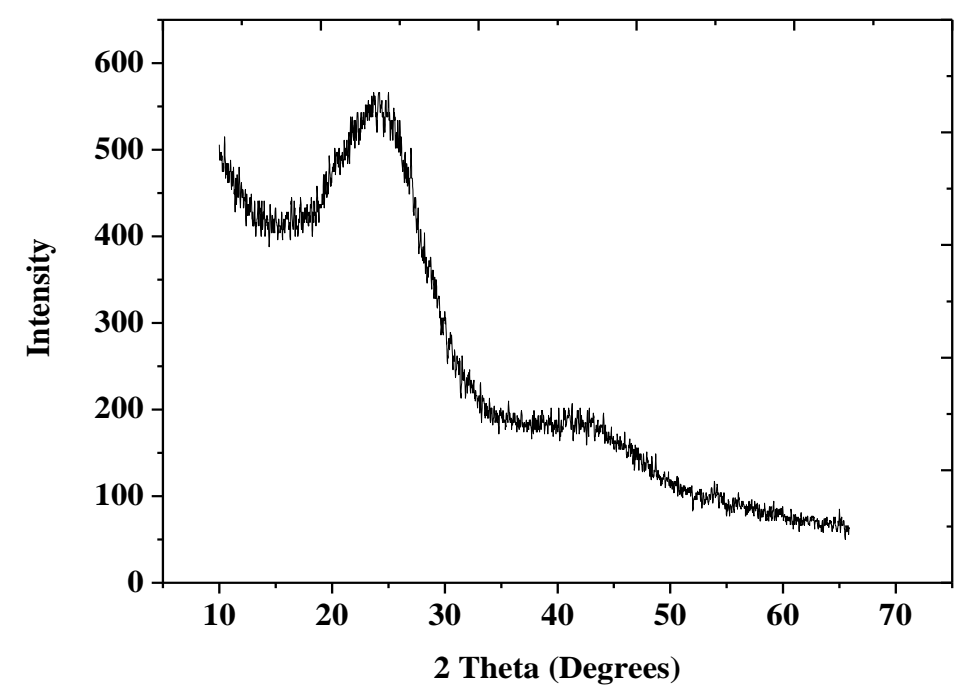

Figure 1. The X-ray diffraction profile (diffractogram) of pine sawdust.

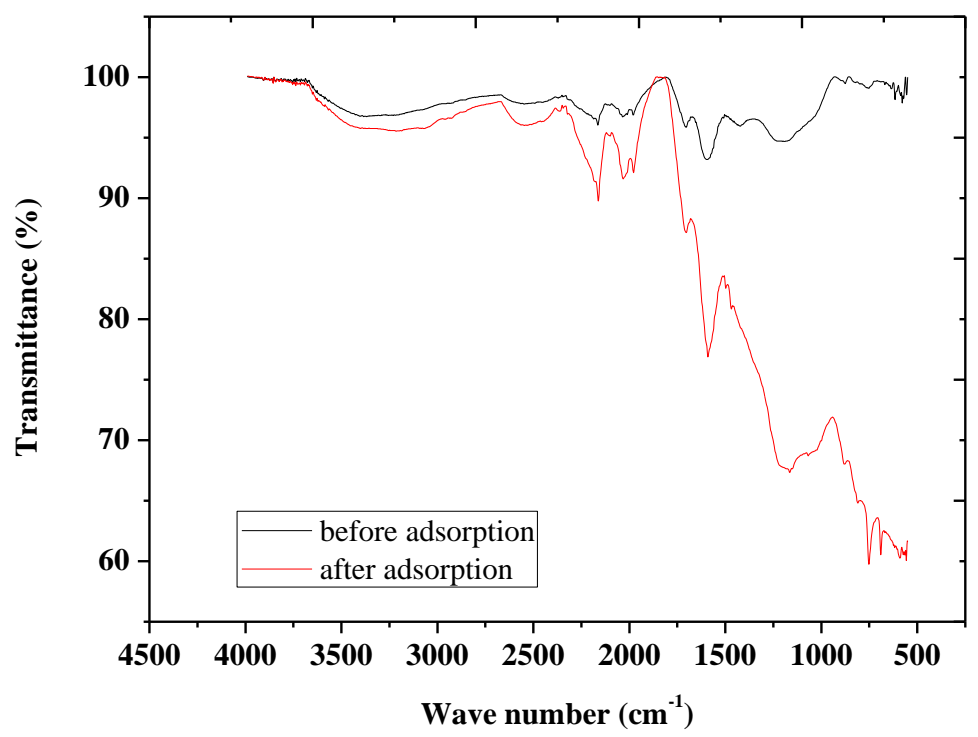

Figure 2. FT-IR spectra of pine sawdust before and after adsorption of cobalt ions.

where $K_{\mathrm{F}}$ is the Freundlich constant related with adsorption capacity $(\mathrm{mg} / \mathrm{g})$ and $n$ is the heterogeneity coefficient (dimensionless).

\section{RESULTS}

\section{Characterization of the adsorbent}

The X-ray diffraction (XRD) technique is a powerful tool to analyze the crystalline nature of the materials. The Xray diffraction pattern of pine sawdust presented in Figure 1 shows two very broad diffraction peaks; a major peak appears at 25 and a minor one at 40 degrees. The spectra shown in Figure 2 display a number of absorption peaks, indicating the complex nature of the surfaces of pine sawdust. Between the wave number of 2250 and $4000 \mathrm{~cm}^{-1}$, the transmittance for sawdust before and after adsorption did not change much. However, between 1750 and $750 \mathrm{~cm}^{-1}$ the transmittance after adsorption was significantly lower than that for the sawdust before adsorption. The SEM image analysis of pine sawdust presented in Figure 3 reveals that the surfaces are rough and protrusions can be seen throughout the micrographs.

It is clear that the modified pine sawdust (Figure 3b), has a considerable number of pores and there is good possibility for cobalt to be adsorbed into these pores as 

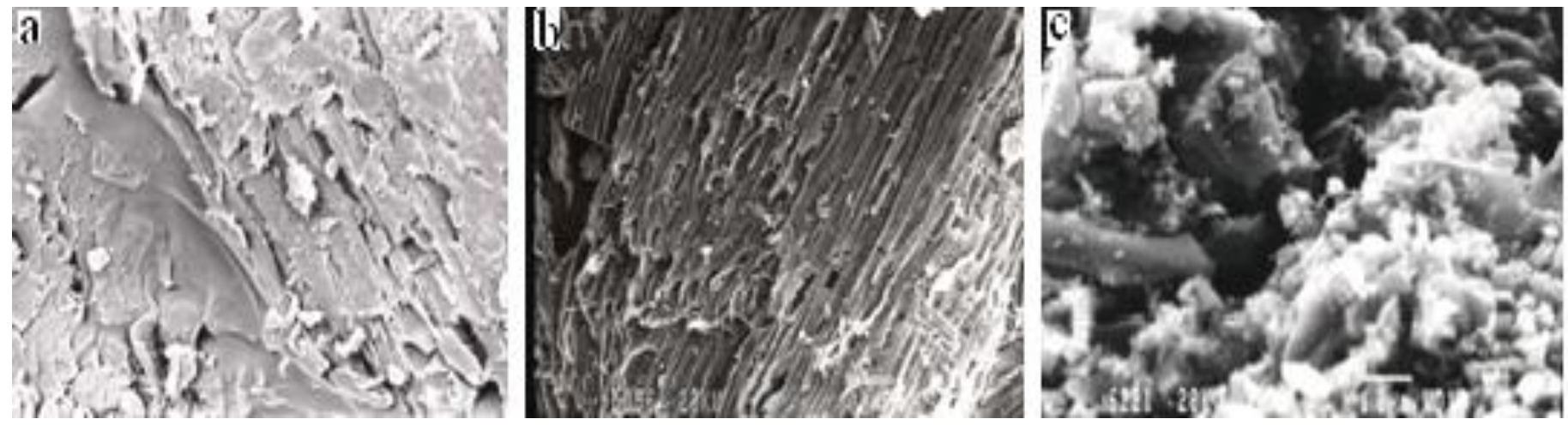

Figure 3. SEM images of pine sawdust (a) before surface modification (b) after surface modification and (c) after adsorption at 400 times magnification.

Table 3. Analysis of variance (ANOVA) for the quadratic model.

\begin{tabular}{lccccc}
\hline Source of variation & Sum of squares & Degree of freedom & Mean square & $\boldsymbol{F}$-value & Probability $>\boldsymbol{F}$ \\
\hline Model & $2.17 \mathrm{E}-03$ & 7 & $3.11 \mathrm{E}-004$ & 12.77 & 0.0134 \\
Residual & $9.75 \mathrm{E}-05$ & 4 & $2.44 \mathrm{E}-005$ & & \\
Lack of fit & $9.75 \mathrm{E}-05$ & 1 & $9.74 \mathrm{E}-005$ & 5.01 & 0.0503 \\
Pure error & $2.97 \mathrm{E}-08$ & 3 & $9.89 \mathrm{E}-009$ & & \\
Total & $2.28 \mathrm{E}-03$ & 11 & & & \\
\hline
\end{tabular}

$R^{2}=0.9572$.

compared to the raw material (Figure 3a). Surface coverage in the form of flakes indicates the presence of inorganic elements that could be heavy metals especially after adsorption (Figure 3c).

\section{Fitting of a quadratic model}

By applying multiple regression analysis methods, the predicted adsorption capacities can be obtained and given as:

$q_{C o}=0.993+0.0157 x_{2}-0.0008 x_{1} x_{3}-0.0279 x_{2} x_{3}+1.04 x_{3}^{2}$

where $q_{c_{0}}$ is the predicted adsorption capacity for cobalt ions and $x_{1}, x_{2}, x_{3}$ are the coded values of the test variables, adsorbent dose $(\mathrm{g} / \mathrm{L}), \mathrm{pH}$ and initial concentration $(\mathrm{mg} / \mathrm{l})$, respectively. The statistical significance of the second order model equation was evaluated by the $F$ test and the analysis of variance (ANOVA) which is summarized in Table 3. In this work, the model acceptance was made on the basis of $95 \%$ confidence level. A low standard deviation of $4.94 \times 10^{-3}$ indicates a better precision and reliability of the experiments carried out. The model presented a relatively high $R^{2}$ value (0.9572) explaining $95.72 \%$ of the varia-bles; dose, $\mathrm{pH}$ and initial concentration in the response and it indicates that $4.28 \%$ of the total variation is not explained by the model.

The model equation (6) has dimensionless input values that is, it consist of coded variables only. However, in practical cases a model equation with the real variables must be used. Thus, the relationship between each coded and real variable were deduced from equation 1 and substituted into the model equation (6) upon rearrangement, from which equation 7 was obtained:

$$
q_{C o}=1.76+0.0299 p H-0.000201 \text { Dose. } C_{o}-0.0101 p H . C_{o}+0.59 C_{o}^{2}
$$

Equation 7 was then used to plot the three dimensional surfaces depicting the interactive effects of adsorbent dose and $\mathrm{pH}$ at constant $C_{0}$ (Figure 4), adsorbent dose and $C_{0}$ at constant $\mathrm{pH}$ (Figure $5 \mathrm{a}$ ), $\mathrm{pH}$ and $C_{0}$ at constant adsorbent dose (Figure 5b), on the adsorption capacity of pine sawdust for cobalt.

Table 2 lists the experimental adsorption capacities obtained for different combinations of the three factors namely: adsorbent dose, $\mathrm{pH}$ and initial concentration. Runs 8 to 12 refer to centre points corresponding to the zero level of each factor. The highest adsorption capacity obtained was $56 \times 10^{-3} \mathrm{mg} / \mathrm{g}$, which occurred at low adsorbent dose and high initial concentration and $\mathrm{pH}$. Figure 4 shows that low adsorbent doses resulted in high adsorption capacities $\left(q_{\mathrm{e}}\right)$, while high doses resulted in low $q_{\mathrm{e}}$ values. At the same time, the adsorption capacity 


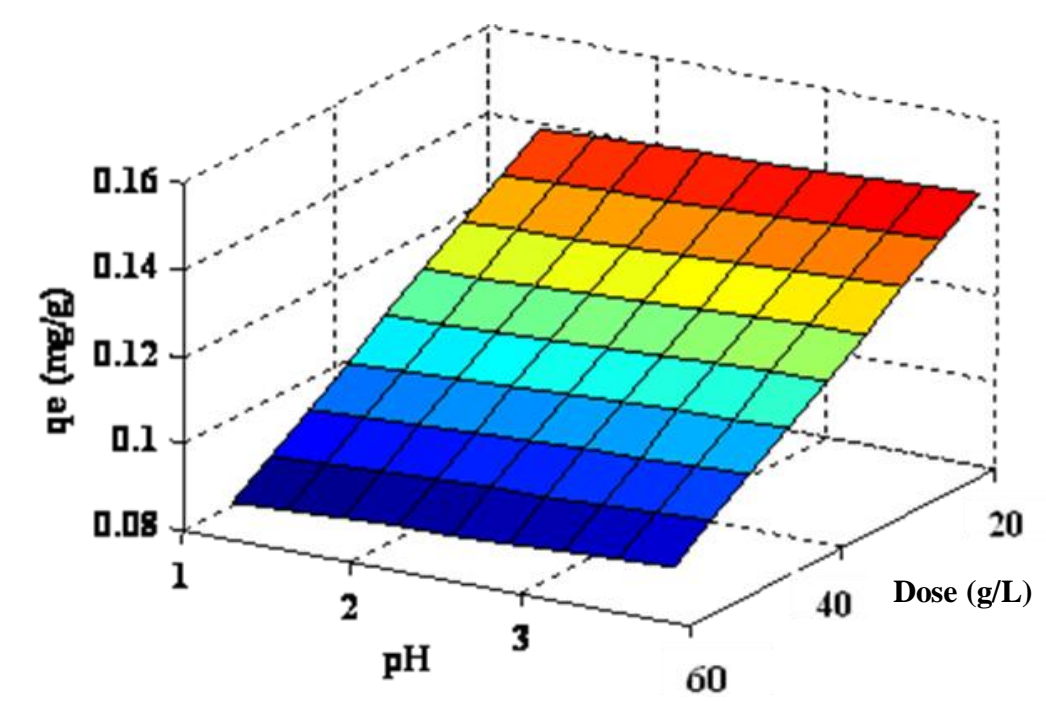

Figure 4. The response surface plot showing the interactive effects of $\mathrm{pH}$ and adsorbent dose on adsorption capacity at constant initial concentration.

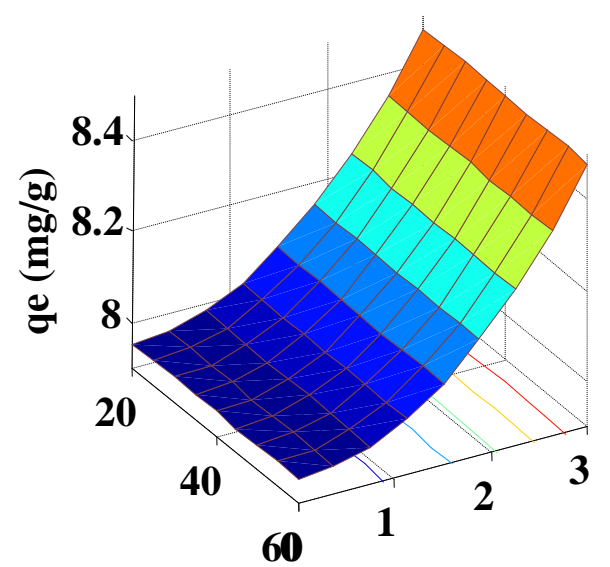

Dose $(\mathrm{g} / \mathrm{L}) \quad$ Co $(\mathrm{mg} / \mathrm{L})$

(a)

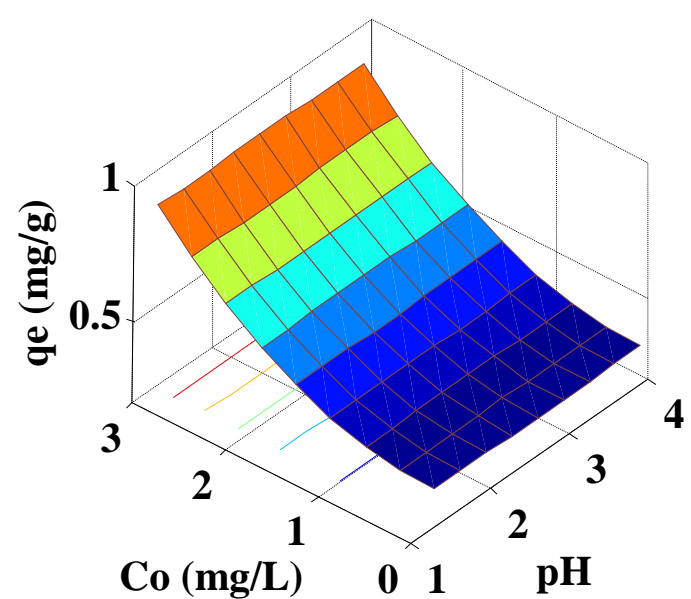

(b)

Figure 5. The response surface plot showing the interactive effects of (a) adsorbent dose and initial concentration at constant $\mathrm{pH}$ and (b) initial concentration and $\mathrm{pH}$ at constant adsorbent dose.

increased with increasing solution $\mathrm{pH}$. Thus, the removal of cobalt increases with increasing $\mathrm{pH}$ and decreasing adsorbent dose. This trend predicted by the model is consistent with the experimental results shown in Table 2 , in which the highest adsorption capacity of $56 \times 10^{-3}$ $\mathrm{mg} / \mathrm{g}$ was observed at low adsorbent dose and high $\mathrm{pH}$.

\section{Equilibrium modelling}

The adsorption data was correlated with commonly used adsorption isotherms namely; Freundlich and Langmuir models. Freundlich isotherm was obtained by plotting $q_{e}$ versus $C_{e}$ on a logarithmic scale (Figure $6 \mathrm{a}$ ), whereas the Langmuir isotherm was obtained by plotting $1 / q_{e}$ versus $1 / C_{e}$ (Figure $6 b$ ). Furthermore, all the isotherm constants (model parameters) together with the $R^{2}$ values (goodness of fit criterion) computed by linear regression for the two types of isotherms were summarized in Table 4.

\section{DISCUSSION}

The absence of a sharp peak for the XRD analysis of pine sawdust in Figure 1 shows that the major part of the 


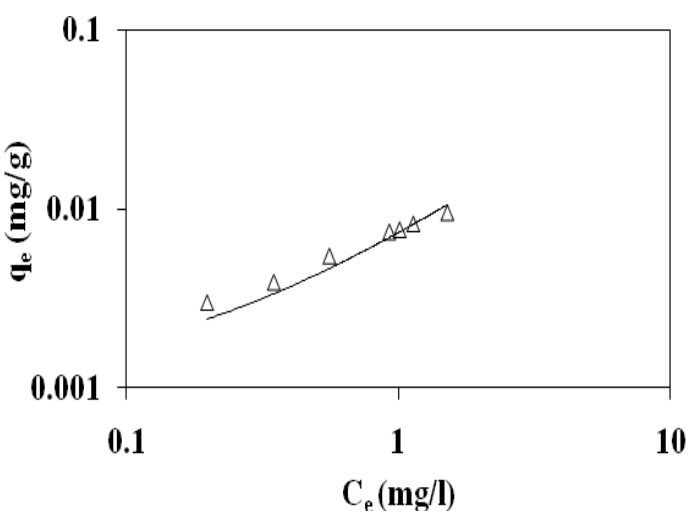

(a)

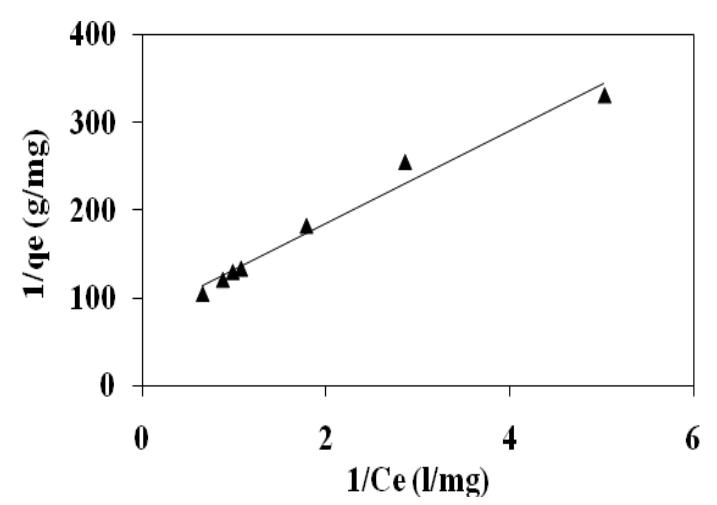

(b)

Figure 6. Linear regression analysis for: (a) Freundlich and (b) Langmuir adsorption isotherm.

Table 4. Adsorption isotherm constants.

\begin{tabular}{lcccccc}
\hline \multirow{2}{*}{ Metal ion } & \multicolumn{3}{c}{ Freundlich } & \multicolumn{3}{c}{ Langmuir } \\
\cline { 2 - 7 } & $\mathbf{1} / \boldsymbol{n}$ & $\boldsymbol{K}_{\boldsymbol{F}}(\mathbf{m g} / \mathbf{g})$ & $\boldsymbol{R}^{2}$ & $\boldsymbol{q}_{\max }(\mathbf{m g} / \mathbf{g})$ & $\boldsymbol{K}_{L}(\mathrm{I} / \mathbf{m g})$ & $\boldsymbol{R}^{2}$ \\
\hline Cobalt (II) & 0.2151 & 0.0054 & 0.9860 & 0.0111 & 0.8810 & 0.9764 \\
\hline
\end{tabular}

adsorbent is amorphous. This is an advantageous property for a good adsorbent (Madhava et al., 2008). The only two broad peaks at around 24.4 and $42.3^{\circ}$ could be attributed to the presence of carbon and graphite (Bouchelta et al., 2008). If the material under investigation is crystalline, well-defined peaks are observed while non-crystalline or amorphous systems show a hollow instead of well-defined peak (Namasivayam and Kavitha, 2006). It has been proved that pine sawdust is amorphous. On the other hand, it has been shown that citric acid provides additional carboxyl groups to those on pine sawdust surfaces and substantially increases its metal uptake capacity (Mcsweeny et al., 2006). Also, from the particle morphology, it is apparent that pine sawdust is suitable to be used as an adsorbent.

The peak at $3381.2 \mathrm{~cm}^{-1}$ before adsorption (Figure 2) can be attributed to the hydrogen-bonded $\mathrm{OH}$ group of alcohols and phenols (Yang and Lua, 2003) and it shifted to $3217.2 \mathrm{~cm}^{-1}$ after adsorption. Further, the peak at $1184.3 \mathrm{~cm}^{-1}$ before adsorption is associated with $\mathrm{C}-\mathrm{O}$ stretching vibrations in carboxylic acids (Pavia and Lampman, 1987) and it shifted to $1163.1 \mathrm{~cm}^{-1}$ after adsorption. These major shifts in band suggest that the alcohols/phenols and carboxylic acid groups were involved in metal binding. Agricultural biomasses mainly consist of lignin, cellulose, hemicelluloses and some proteins, which make them effective adsorbents for heavy metal cations (Garg et al., 2008). Additionally, the band at $1597.0 \mathrm{~cm}^{-1}$ represents the $\mathrm{C}=\mathrm{C}$ skeletal stretch in condensed aromatic system and a peak at $754.2 .3 \mathrm{~cm}^{-1}$ can be assigned to the out-of-plane $\mathrm{C}-\mathrm{H}$ bending modes of an aromatic compound (Al-Qodah and Shawabkah, 2009).

It can be assumed from the results presented in Table 2, Figure 4 and the FT-IR spectra that the possible adsorption mechanism is probably due to ion exchange. High concentration of $\mathrm{H}^{+}$ions at low $\mathrm{pH}$ of 1.3 may change the direction of reversible ion exchange equilibrium back to starting materials to give low $q_{\mathrm{e}}$ values (Yu et al., 2001). At a high $\mathrm{pH}$ of 3.9, relatively low concentration of $\mathrm{H}^{+}$ions means less competition for the adsorption site on sawdust particles which result in high $q_{\mathrm{e}}$ values for cobalt ions. The FT-IR spectra showed that the $-\mathrm{OH}$ and $-\mathrm{COOH}$ groups took part in the sorption process. However, the sites responsible for the sorption process might not be exclusively due to the $-\mathrm{OH}$ and $-\mathrm{COOH}$ groups, other sites on the adsorbent may also contribute to the sorption process and physical adsorption is quite probable (Yu et al., 2001).

In order for a term to be significant at the $95 \%$ confidence level (Table 3 ), the calculated probability should be lower than 0.05 (Bhatia et al., 2009). The ANOVA test revealed that this regression model is statistically significant, as is evident from the Fisher's F-test with a very low probability value $(<0.0134)$; the associated Prob. $>F$ value for the model is lower than 0.05 . The lackof-fit measures the failure of the model to represent data in the experimental domain at points which are not included in the regression. The associated Prob. $F$ for the lack-of-fit is 0.0503 which is greater than 0.05 and this indicates that the lack-of fit is not significant. Thus, the non-significant value of lack of fit $(>0.05)$ reveals that 
the quadratic model is statistically significant (Sharma et al., 2009). The decrease in adsorption capacity with increase in adsorbent dose (Figure 4) could be due to the aggregation or overlapping of adsorption sites caused by overcrowding of the sawdust particles. Such aggregation would lead to decrease in total surface area of the adsorbent and an increase in diffusional path length (Shukla et al., 2002). This trend is comparable to that reported by Ayyappan et al. (2003) for the removal of $\mathrm{Pb}$ (II) from aqueous solution using a low cost adsorbent. Figures $5 \mathrm{a}$ and $\mathrm{b}$ shows that the adsorption capacity of pine sawdust for cobalt ions increased with increasing initial concentration. This trend can be explained by the fact that initial concentration provides a significant driving force of the concentration gradient to overcome all the mass transfer resistance between the solid and aqueous phase. This is in agreement with the findings of Ghorbani et al. (2008).

The Freundlich model presented a high correlation coefficient $\left(R^{2}=0.9860\right)$ as compared to $(0.9764)$ for the Langmuir model. Thus, it is evident that the equilibrium data conforms to the Freundlich model, which assumes heterogeneity in the surface binding process. This observation is consistent with the heterogeneous nature of pine sawdust which consists of different active sites such as $-\mathrm{OH}$ and $-\mathrm{COOH}$ groups as revealed by the FT-IR spectra. The Langmuir model assumes homogeneity (all the active sites possess equal affinity) in the surface binding process and that is why it could not fit well to the experimental data. Moreover, agricultural adsorbents display heterogeneity (Gupta and Ali, 2004). Such observation was also reported by Fritz and Schlünder (1981). The intensity of adsorption $(1 / n)$, lies between 0 and 1, which implies stronger interaction between the pine sawdust and the cobalt (II) ions (Site, 2001). Disposal of pine sawdust after use can be accomplished by either composting or incineration (Marshall and Johns, 1996) and the metal residues could be recovered by subsequent treatment of the postcombustion ash (Wase and Forster, 1997).

\section{Conclusion}

Agricultural waste has been employed to treat synthetic industrial wastewater in a batch system. Following the batch adsorption experiments, the data obtained was used to calculate the adsorption capacity, model adsorption isotherms and conduct a response surface analysis. It was found that adsorbent dose, $\mathrm{pH}$ and initial concentration have a notable effect on the uptake of cobalt by the pine sawdust. Low adsorbent doses and high initial concentrations resulted in high adsorption capacities. Furthermore, a high $\mathrm{pH}$ in combination with the above factors resulted in the highest adsorption capacity of $56 \times$ $10^{-3} \mathrm{mg} / \mathrm{g}$. Hence, the area of high initial concentration and $\mathrm{pH}$ and low adsorbent dose, should be the focus of future research.
Fitting the experimental data to a second order response surface model resulted in the model slightly overpredicting the adsorption capacities. However, surface plots revealed that the general trend shown by the experimental data was evident in the model; that is, adsorption capacity increased with increasing initial concentration and $\mathrm{pH}$ and decreasing adsorbent dose. The second order response surface model was also found to be statistically significant. On the other hand, the experimental data was better described by the Freundlich isotherm than the Langmuir isotherm since pine sawdust conformed to the assumption of heterogeneity in the surface binding process. Moreover, pine sawdust has shown adsorption capabilities for cobalt, and hence it could be an option in the quest to use waste to treat wastewater. However, the adsorption capacity of the saw dust needs to be improved for its application to be economical.

\section{REFERENCES}

Al-Degs YS, El-Barghouthi MI, Issa AA, Khraisheh MA, Walker GM (2006). Sorption of $\mathrm{Zn}(\mathrm{II}), \mathrm{Pb}(\mathrm{II})$ and $\mathrm{Co}(\mathrm{II})$ using natural sorbents: Equilibrium and kinetic studies. Water Res. 40: 2645-2658.

Al-Qodah Z, Shawabkah R (2009). Production and characterization of granular activated carbon from activated sludge. Braz. J. Chem. Eng. 26: 127-136.

Argun ME, Dursun S, Ozdemir C, Karatas M (2007). Heavy metal adsorption by modified oak sawdust: Thermodynamics and kinetics. J. Hazard. Mater. 141: 77-85.

Ayyappan R, Sophia AC, Swaminathan K, Sandhya S (2003). Removal of $\mathrm{Pb}$ (II) from aqueous solution using carbon derived from agricultural wastes. Process Biochem. 40: 1293-1299.

Azhar SS, Liew AG, Suhardy D, Hafiz KF, Hatim MDI. (2005). Dye removal from aqueous solution by using adsorption on treated sugarcane bagasse. Am. J. Appl. Sci. 11: 1499-1503.

Bouchelta C, Medjram MS, Bertrand O, Bellat JP (2008). Preparation an d characterization of activated carbon from date stones by physical activation with steam. J. Anal. Appl Pyrol. 82: 70-77.

Bhatia S, Wong CT, Abdullah AZ (2009). Optimization of air-borne butyl acetate adsorption on dual-function $\mathrm{Ag}-\mathrm{Y}$ adsorbent-catalyst using response surface methodology. J. Hazard. Mater. 164: 1110-1117.

Cavaco SA, Fernandes S, Quina MM, Ferreira LM (2007). Removal of chromium from electroplating industry effluents by ion exchange resins. J. Hazard. Mater. 144: 634-638.

Elibol M (2002). Response surface methodological approach for inclusion of perfluorocarbon in actinorhodin fermentation medium. Process Biochem. 38: 667-773.

Febrianto J, Kosasih AN, Sunarso J, Ju Y, Indraswati N, Ismadji S (2009). Equilibrium and kinetic studies in adsorption of heavy metals using biosorbent: A summary of recent studies. J. Hazard. Mater. 162: 616-645.

Fritz W, Schlünder EU (1981). Competitive adsorption of two dissolved organics onto activated carbon. Chem. Eng. Sci. 36: 721-730.

Garg U, Kaur MP, Jawa GK, Sud D, Garg VK (2008). Removal of cadmium (II) from aqueous solutions by adsorption on agricultural waste biomass. J. Hazard. Mater. 154: 1149-1157.

Ghorbani F, Younesi H, Seyed MG, Ali AZ, Amini M, Danesh A (2008). Application of response surface methodology for optimization of cadmium biosorption in an aqueous solution by Saccharomyces cerevisiae. Chem. Eng. J. 145: 267-275.

Gupta VK, Ali I (2004). Removal of lead and chromium from wastewater using bagasse fly ash-a sugar industry waste. J. Colloid Interface Sci. 271: 321-328.

Kumar U (2006). Agricultural products and by-products as a low cost 
adsorbent for heavy metal removal from water and wastewater: A review. Sci. Res. Essay, 1: 033-037.

Kumar U, Bandyopadhyay M (2006). Sorption of cadmium from aqueous solution using pretreated rice husk. Bioresour. Technol. 97: 104-109.

Kurt K, Apaydin O, Gonullu MT, (2007). Reduction of COD in wastewater from an organized tannery industrial region by ElectroFenton process. J. Hazard. Mater. 143: 33-40.

Linna A, Oska P, Palmroos P, Roto P, Laippala P, Uitti J (2003). Respiratory health of cobalt production workers. Am. J. Ind. Med. 44: 124-132.

Madhava RM, Reddy DHKK, Venkateswarlu P, Seshaiah K (2009). Removal of mercury from aqueous solutions using activated carbon prepared from agricultural by-product/waste. J. Environ. Manage. 90: 634-643.

Marshall WE, Johns MM (1996). Agricultural by-products as metal adsorbents: sorption properties and resistance to mechanical abrasion. J. Chem. Technol. Biotechnol. 66: 192-198.

Mavrov V, Stamenov S, Todorova E, Chmiel H, Erwe T (2006). Removal of nickel ions from wastewater by $\mathrm{Mg}(\mathrm{OH}) 2 / \mathrm{MgO}$ nanostructures embedded in $\mathrm{Al}_{2} \mathrm{O}_{3}$ membranes. J. Alloys Compd. 426: 281-285.

McSweeny JD, Rowell RM, Min SH (2006). Effect of Citric Acid Modification of Aspen Wood on Sorption of Copper Ion. J. Nat. Fibers, 3: 43-58.

Onyango MS, Kojima Y, Aoyi O, Bernardo EC, Hitoki MH (2004). Adsorption equilibrium modeling and solution chemistry dependence of fluoride removal from water by trivalent-cation-exchanged zeolite F-9. J. Colloid Interface Sci. 279: 341-350.

Patel H, Madamwar D (2002). Effects of temperatures and organic loading rates on bio-methanation of acidic petrochemical wastewater using an anaerobic upflow fixed-film reactor. Bioresour. Technol. 82: 65-71.

Pavia DL, Lampman GM, Kaiz GS (1987). Introduction to Spectroscopy: A Guide for Students of Organic Chemistry, W.B. Saunders Company, Philadelphia.

Ravikumar K, Krishnan S, Ramalingam S, Balu K (2007). Optimization of process variables by the application of response surface methodology for dye removal using a novel adsorbent. Dyes Pigments, 72: 66-74.
Rangaraj S, Moon SH (2002). Kinetics of adsorption of Co(II) removal from water and wastewater by ion exchange resins. Water Res. 36: 1783-1793.

Sharma P, Singh L, Dilbaghi N (2009). Optimization of process variables for decolorization of Disperse Yellow 211 by Bacillus subtilis using Box-Behnken design. J. Hazard Mater. 164: 1024-1029.

Shukla A, Zhang Y, Dubey P, Margrave JL, Shukla SS (2002). The role of sawdust in the removal of unwanted materials from water. J. Hazard Mater. B95: 137-152.

Singh R, Moodley K, Onyango, MS, Odiyo JO, Aoyi O (2007). Use of agricultural wastes to treat industrial wastewater: Review. Egerton University Research Week and Internat ional Conference, Njoro, Kenya, 483-490.

Site AD (2001). Factors affecting sorption of organic compounds in natural sorbent/water systems and sorption coefficients for selected pollutants: A review. J. Phys. Chem. Ref. Data 30: 187-439.

Wafwoyo W, Seo CW, Marshall WE (1999). Utilization of peanut shells as adsorbents for selected metals. J. Chem. Technol. Biotechnol. 74: 1117-1121.

Wase DAJ, Forster CF (1997). Biosorbents for metal ions, Taylor and Francis, London.

World Bank Group (1998). Pollution Prevention and Abatement Handbo ok: Towards Cleaner Production, World Bank, Washington, D.C, 371376.

http://www.scribd.com/doc/12239840/Pollution-Prevention-AbatementHandbook-1998 (Accessed on 02 February 2009).

Yang T, Lua A (2003). Characteristics of activated carbons prepared from pistachio-nut shells by physical activation. J. Colloid Interface Sci. 267: 408-417.

Yu B, Zhang Y, Shukla A, Shukla SS, Dorris KL (2001). The removal of heavy metals from aqueous solutions by sawdust adsorption-removal of lead and comparison of its adsorption with copper. J. Hazard Mater. 84: 83-94. 